This is an electronic reprint of the original article. This reprint may differ from the original in pagination and typographic detail.

Author(s): Engelbrecht, Petra; Savolainen, Hannu

Title: $\quad$ A mixed-methods approach to developing an understanding of teachers' attitudes and their enactment of inclusive education

Year: $\quad 2018$

Version:

Please cite the original version:

Engelbrecht, P., \& Savolainen, H. (2018). A mixed-methods approach to developing an understanding of teachers' attitudes and their enactment of inclusive education. European Journal of Special Needs Education, 33(5), 660-676.

https://doi.org/10.1080/08856257.2017.1410327

All material supplied via JYX is protected by copyright and other intellectual property rights, and duplication or sale of all or part of any of the repository collections is not permitted, except that material may be duplicated by you for your research use or educational purposes in electronic or print form. You must obtain permission for any other use. Electronic or print copies may not be offered, whether for sale or otherwise to anyone who is not an authorised user. 


\section{A MIXED-METHODS APPROACH TO DEVELOPING AN UNDERSTANDING OF TEACHERS' ATTITUDES AND THEIR ENACTMENT OF INCLUSIVE EDUCATION}

Petra Engelbrecht*

Faculty of Education Sciences

North-West University-Potchefstroom Campus

Private Bag X6001

Hoffmanstreet

Potchefstroom

South Africa

Telephone: +27829211879

petra.engelbrecht50@gmail.com

Hannu Savolainen

Department of Education

University of Jyvaskyla

40014 University of Jyvaskyla

Finland

Telephone:+358408054892

hannu.k.savolainen@jyu.fi

http://orchid.org/0000-0002-1264-3746

*Contact: petra.engelbrecht50@gmail.com 


\section{ABSTRACT}

This research sought to develop an understanding of teachers' attitudes, sense of selfefficacy and approach to enacting inclusive education in their classrooms. A mixed-methods research design guided the data collection and analysis. This article focuses on how quantitative and qualitative research approaches were used sequentially and how the findings were finally merged to provide more comprehensive insight into different aspects of teachers' sometimes contradictory attitudes and approaches to implementing inclusive education. The meta-inferences presented here indicate that merging measurements and meanings can shed light on how teachers' attitudes and self-efficacy within the implementation of inclusive education are multi-faceted, non-linear and connected to their cultural-historical contexts. 


\section{INTRODUCTION}

The research discussed in this paper originated in discussions between two university colleagues, one in South Africa and the other in Finland, about the roles of teachers in inclusive classrooms in a lower-income country and a higher-income country and the importance of initial and continuing professional development of teachers in these two diverse countries. Research has indicated that the roles of teachers and the ways in which they practice inclusion in inclusive classrooms should be examined more closely against the background of their own attitudes towards inclusive education in order to develop more effective initial as well as continuing teacher education for inclusion programmes. Teachers' personal interpretations and understanding of their own roles play a critical role in this regard (Jordan, Schwartz \& M cGhie-Richmond, 2009; Swart \& Oswald, 2009; Oswald, 2014 ).

The authors therefore realised that, before professional development programmes could possibly be reformed, they needed more information about teachers' attitudes towards inclusion as well as the way in which inclusive education is enacted in their classrooms. To do so, a comparative research project with a sequential mixed-methods research design was conceptualised (Authors, 2012a; Creswell \& Plano Clark, 2007; Authors, 2017).

This paper specifically reports on the multi-phased approach to the research design with an emphasis on the resultant meta-inferences from the merging of the quantitative and qualitative phases during the third phase (M ertens, 2005; Teddlie $\&$ Tashakkori, 2009). When combined, a non-linear and fluid connection emerged between these findings in the data.

\section{A COM PARATIVE APPROACH TO THE ROLE OF TEACHERS IN THE IM PLEM ENTATION OF INCLUSIVE EDUCATION IN FINLAND AND SOUTH AFRICA}


Despite multiple meanings being attached to the concept, and acknowledging that the meaning of 'inclusion' can take different forms in different places, internationally inclusive education is based on a broad understanding of inclusive education (UNESCO, 2009; Waitoller \& Artiles, 2013). This broader understanding includes not only access to general education classrooms for students with a wide variety of learning needs but also acceptance, participation and the promise of quality education for all (Waitoller \& Artiles, 2013). This international definition formed the point of departure for our understanding of inclusive education within this project and realisation that inclusive schools are about belonging, nurturing and education for all students regardless of their differences in ability, culture, gender, language, class and ethnicity (Ferri, 2015; Florian, 2014; Kozleski, Artiles, \& Waitoller, 2011). Furthermore, the research project discussed in this article was placed within a cultural-historical framew ork to provide the researchers with critical insights into how teachers' attitudes could be embedded in cultural milieus and how local actions in classrooms are connected to larger historical processes. The term 'cultural-historical' is used in a broad sense to identify wider cultural-historical change processes in education, with specific reference to the mediating force of history and culture on the development of inclusive education (Authors, 2013a; Kozleski, Artiles, \& Waitoller, 2011; Authors, 2017).

\section{Development of inclusive education in Finland}

The Finnish school system was reformed in the early 1970s into comprehensive schools for all. The subsequent development and implementation of inclusive education in Finland has a strong focus on pragmatic issues, especially on what comprises the best learning environment for students with various learning needs and on the specific consequences of including a student with a disability in a mainstream classroom. Comprehensive schools in Finland have retained some aspects of separate special education, even though the reform adopted in the 1970s aimed to increase socio-cultural, geographical and gender equity (Kivirauma, Klemelä, \& Rinne, 2006). An example of this is the increase in the number of students being identified as having special educational needs that lasted until 2010. This identification relied heavily on statements made by medical doctors and psychologists. Special education support in mainstream schools still largely relies on a 'pull-out' model of instruction where individual students are taken out of the classroom for individual support (Takala, Pirttimaa \& Törmälä, 2009). As a result, at the beginning of data collection for this study, Finnish comprehensive schools had a high proportion of students formally identified as having special educational needs ( $8.5 \%$ ) and a large number of learners receiving parttime special education (23.3\%) in mainstream schools (Official Statistics of Finland, 2011).

A systematic reform in recent years has sought to move Finnish schools towards a more inclusive direction through a new Special Education Strategy (Finnish M inistry of Education and Culture, 2007), the Revised Act on Basic Education (Finnish Basic Education Act, 2010) and the updated National Curriculum Guidelines (National Board of Education, 2010). According to the Revised Act on Basic Education (2010), schools are now required - more 
directly than before - to show evidence of adequate learning support in mainstream classrooms before any student can be given more intensive learning support, and decisions about a student's needs are now principally based on a review by their teacher. It should be noted, however, that no definition of inclusive education is included in any law or policy, and the only reference to what could be defined as inclusive education states (Finnish Basic Education Act, 2010) that, unless a child's needs or the situation otherwise requires, the primary learning context should be the mainstream classroom.

\section{Development of inclusive education in South Africa}

In South Africa under the apartheid government, education provision and learning support operated along racial and ability lines and were managed in various state departments characterised by vast disparities in funding, resources, educational rights, opportunities and expectations for learners with special educational needs (Walton, 2011). In the postapartheid era since 1994, new legislation and policies on inclusive education have been formulated that place a strong emphasis on equality and human rights as defined in the Constitution of the Republic of South Africa (RSA, 1996). In 2001, White Paper 6, Special Needs Education, Building an Inclusive Education and Training System (hereafter referred to as White Paper 6) was published (Department of Education [DoE], 2001), acknowledging the failure of the education system to respond to barriers to learning and development experienced by a substantial number of learners, including those with disabilities The policy document describes inclusive education as being based on the ideal of equality and equity and about recognising and respecting learner and learning diversity within mainstream schools. In practice this means identifying and removing barriers in the education system to ensure that the full range of diverse learning needs are met, as well as providing professional support to learners and teachers in addressing barriers to learning and development. It also means implementing good teaching strategies that are learner focused to ensure that all learners benefit from teaching and learning (DoE, 2001). Despite a remaining emphasis on the term 'special educational needs', which are rooted in medical causes, White Paper 6 defines inclusive education as the increasing development of a single system of education within the South African context that is dedicated to ensuring that all learners are enabled to become competent citizens in a changing and diverse society in which diverse educational needs are a strength rather than a liability.

Recent research studies on the implementation of inclusive education in South Africa, however, have found that, despite the development of implementation guidelines (e.g. DBE, 2010), complex contextual issues - such as funding constraints that affect the availability of resources and resultant overcrow ded classrooms and negative school cultures that influence attitudes towards difference and disability - still complicate the implementation of White Paper 6's recommendations (Authors, 2016b; Swart \& Oswald, 2009; Walton, 2011). The Department of Basic Education (DBE) stresses in 2015 that both incoherent conception and understanding of the strategic intent as well as the practical approach as articulated in White Paper 6 towards developing inclusive schools on all levels of the system continue to impede progress towards a truly inclusive education and training system (Department of Basic Education, 2015). 


\section{Role of teachers in inclusive education}

Despite the different trajectories that the development of inclusive education has taken in these two diverse countries, teachers in both countries continuously have to develop strategies to provide quality educational opportunities for each learner in their classrooms. Furthermore, classroom contexts in both countries are increasingly characterised by a complex constellation of diverse learning needs, including those caused by social class, ethnicity, home language, gender and ability or disability (Authors, 2013a; Authors 2012a; Authors, 2017; Jahnukainen \& Itkonen, 2016; Oswald, 2014). However, in South Africa, despite the publication of White Paper 6 , teacher education programmes continue to emphasise a medical deficit approach, where specialised intervention by specialists is recommended (Nel, Tlale, Engelbrecht \& Nel, 2016; Walton, 2011; Walton \& Rusznyak, 2016). In Finland, despite the general acceptance of moving towards more inclusive education, teacher education programmes have not been modified accordingly and thus mainstream teachers who received no training in inclusive education feel they are not fully confident or have enough skills for teaching students with diverse needs (Paju, Räty, Pirttimaa, \& Kontu, 2016).

Analysis of the current research on inclusive education in both countries indicates that findings on the implementation of inclusive education and the role of teachers have tended to be based on either survey research (e.g. Nel et al., 2011; Paju et al., 2016)) or qualitative research (e.g. Geldenhuys \& Wevers, 2013; Oswald, 2014; Pesonen, Kontu, Aarinen, \& Pirttimaa, 2016; Walton, 2011). Therefore, by combining quantitative and qualitative data in a sequential mixed method research design, the authors aimed to provide a more complete picture not only of teachers' roles in inclusive education in general but in-depth knowledge of participants' perspectives as well (Creswell \& Plano Clark, 2007).

\section{DEVELOPING A RESEARCH DESIGN}

\section{Research design}

First, quantitative and qualitative data were combined in a sequential explanatory mixedmethods research design to aid the researchers in surveying teachers' attitudes towards inclusive education and their sense of self-efficacy in implementing inclusive education. Second, the mixed-methods approach, against the background of the quantitative data findings, helped the researchers develop an understanding of how teachers' perceptions are reflected in their teaching and support strategies in their own classrooms. Triangulation, as well as peer evaluation, was used to secure an in-depth understanding of teachers' perceptions and to provide richness to the understanding of how inclusive education is enacted in classrooms (Authors, 2012a; Mertens, 2005; Teddlie \& Tashakkori, 2009; Authors, 2015). Data was collected and analysed between 2011 and 2016.

Initially, a two-phased approach was decided upon: during Phase 1, a larger scale quantitative survey research approach provided the researchers with an overview of the 
attitudes and sense of self-efficacy of teachers in both countries towards inclusive education, as well as a sense of the way in which cultural-historical influences might affect teachers' perceptions (Authors, 2014). The overall research question and resultant subquestions for this quantitative phase of the research, placed within a positivist research paradigm (M ertens, 2009), were as follows:

What are teachers' sentiments, attitudes and concerns, as well as perceived self-efficacy, related to inclusive education?

To allow for a more in-depth exploration of the differences and similarities in profiles of attitudes and self-efficacy and their effect on teachers' classrooms across settings, Phase 2 of the project was qualitative in nature and was placed within an interpretivist research paradigm (M ertens, 2009; Teddlie \& Tashakkori, 2009). In this way, the authors could explore not only how teachers enact inclusive education in their own classrooms but also how familiar inclusive educational practices and beliefs in one country might be exposed and questioned when compared with those in another country (Aldridge, Fraser, \& Huang, 1999; Authors, 2013a). The overall research question of this qualitative phase of the comparative research project therefore was based on the quantitative data findings and formulated as follows:

Against the background of teachers' attitudes and sense of self-efficacy, how do teachers in Finland and South Africa make inclusive education meaningful in their classroom practices? However, the authors of this paper realised during Phase 2 of their project that their linear approach to the research design, data collection and analysis (i.e. using the qualitative data to explain the quantitative data in more depth) left them with the following questions:

- How can we move beyond just comparing and contrasting findings during the quantitative and qualitative phases of the research process?

- How can we illustrate how converging or diverging quantitative and qualitative findings could be a dynamic, non-linear process within a broader cultural-historical framework?

The authors therefore decided on a third meta-inferences phase, as discussed by Teddlie and Tashakkori (2009), in which we revisited our quantitative and qualitative findings and integrated our data sets to provide a more complete picture of the findings.

\section{Ethical clearance}

To address possible ethical challenges to how educational research is conceptualised, conducted and disseminated in cross-cultural research, ethical approval was acquired per the guidelines of the relevant universities and school authorities. During this process, the researchers also shared insights with each other on assumptions that shape research and writing practices across cultures, including the role of language and differing definitions of terms associated with the research project (Robinson-Pant \& Singal, 2013). 


\section{Research process}

The final overall research process was divided into three phases: quantitative, qualitative and meta-inference.

\section{- Phase 1: Quantitative phase}

Participants. A sample of 310 South African and 815 Finnish primary and secondary education teachers completed a questionnaire (Authors, 2012a). The South African sample consisted of $270(87.1 \%)$ mainstream teachers and 40 (12.9\%) special education teachers. Of the teachers in the Finnish sample, 688 (84.4\%) were mainstream teachers and 127 (15.6\%) were special education teachers. Although the demographic profile of the samples was similar in terms of gender and average number of years of service as a teacher (e.g. $78.3 \%$ of Finnish respondents and $82.1 \%$ of South African respondents were female and average of years of teaching experience for both groups was 17 years), a large difference existed between the two country samples in levels of professional teacher education degrees. For example, $82.4 \%$ of Finnish participants had a master's degree, in contrast with $2.4 \%$ of South African teachers with a master's degree, $35.9 \%$ with a bachelor's degree or equivalent and $58.5 \%$ with a teacher's diploma. With specific reference to South African teachers, it should be noted that, although teacher education programmes have undergone a radical change since 1994, teacher qualifications still reflect the inequitable and racially segregated teacher education system created by the apartheid government. The result is that most teachers still only have a college teacher training qualification (a teacher's diploma), and a minority of teachers have a university teacher education (bachelor's degree or equivalent; Schafer \& Wilmot, 2012).

Convenience sampling was used both in Finland and South Africa. The Finnish data was collected from six small- to medium-sized municipalities in Eastern Finland and one big municipality in the Southwest. The South African sample was drawn from the Vaal Triangle area, which consists of parts of Gauteng Province and the Free State Province. Schools from different socio-economic and cultural contexts were included in the study.

Data collection methods. The questionnaire was based on two previously published scales, The Sentiments, Attitudes and Concerns about Inclusive Education (SACIE) scale (Loreman, Earle, Sharma, \& Forlin, 2007; Authors, 2012a) and the Teacher Self-Efficacy for Inclusive Practices (TEIP) scale (Sharma, Loreman, \& Forlin, 2012; Authors, 2013c).

The SACIE scale has 15 statements that are rated with a Likert-type scale of four response anchors (strongly agree, agree, disagree and strongly disagree) and measures different aspects of attitudes, ranging from general attitudes towards disabilities (sentiments subscale) to general attitudes towards inclusion (attitudes sub-scale) to specific attitudes towards inclusion in one's own context (concerns). In this study, the total score of the SACIE scale was used as an overall indicator of attitudes containing the three elements described above (Cronbach's alpha scores: Finland=.75; South Africa=.70). 
The TEIP scale (Sharma et al., 2012) measures three types of self-efficacy and they can also be found in the Finnish and South African data (Authors, 2013c; Authors, 2012a). The scale consists of 18 items that are rated on a 6 -point Likert-type scale $(1=$ strongly disagree, $6=$ strongly agree). Higher TEIP-scale scores indicate greater teacher self-efficacy. Of the three sub-scales, one measures teacher self-efficacy in inclusive instruction. Another sub-scale measures self-efficacy in collaboration and the third sub-scale measures self-efficacy in behaviour management. All subscale reliabilities were excellent (Cronbach's alpha: Finland= .90; South Africa $=.91$ )

In addition, the teachers were asked personal background questions (in this study, gender and age) and three questions related to their contextual knowledge and confidence and experience in teaching students with disabilities. Teachers rated these on a scale of 1 to 5 , and an exploratory factor analysis showed that these three variables loaded clearly on one factor and that the three-item scale was internally consistent, as indicated by good reliabilities (Cronbach's alpha: Finland $=.83$; South Africa $=.84$ ).

The South African English-language questionnaires were translated into Finnish by team members based in Finland and then critically reviewed by an English translator before agreement on best wording was reached through negotiation with the research team. Both the English version used in South Africa and the Finnish version used in Finland were piloted, and based on feedback from respondents, some items were modified to better match the cultural-historical contexts of both countries; these issues were also discussed and confirmed by the Finnish South Africa research team.

Data analysis. Data were analysed using the IBM SPSS statistics programme and M PluS programme. The data from both countries were analysed separately, as the objective was to compare the similarities or differences in the results of the country analyses (Authors, 2014).

\section{- Phase II: Qualitative phase}

Participants. The quantitative phase was connected to the qualitative phase by purposefully choosing the participants from among the same country samples that had completed the questionnaire in Phase 1.

Table 1. Profile of participants

\begin{tabular}{|l|l|l|}
\hline Sample & Finland & South Africa \\
\hline Female & 14 & 20 \\
\hline Male & 8 & 3 \\
\hline $\begin{array}{l}\text { Language of learning and } \\
\text { teaching (LOLT) of all schools }\end{array}$ & Finnish & English \\
\hline Qualification & All had an MA degree in & All had either a four-year \\
\hline
\end{tabular}




\begin{tabular}{|l|l|l|}
\hline & $\begin{array}{l}\text { education or special } \\
\text { education }\end{array}$ & $\begin{array}{l}\text { diploma or a degree in } \\
\text { primary education }\end{array}$ \\
\hline Teachers' first language & Finnish & $\begin{array}{l}\text { Afrikaans 5 } \\
\text { English 6 } \\
\text { Sesotho 12 }\end{array}$ \\
\hline
\end{tabular}

In Finland, the data was collected from both rural and urban primary schools $(\mathrm{N}=4)$ in the Eastern Finland region. The interview data consisted of 11 individual interviews and four focus group discussions including 14 female and eight male participants. The teachers were from representative types of regional schools, including a small suburban school, a midsized urban school, a large and growing urban school and small countryside school. The schools take in students from their respective catchment areas, and their student populations represents the mix of backgrounds in these communities. The student population include students that have learning difficulties, mild intellectual disabilities, problems with behaviour or attention-deficit/hyperactivity disorder (ADHD)-related symptoms. Typically, differences between schools with regard to students' social or cultural backgrounds were very small at the time of data collection in regions such as Eastern Finland (Authors, 2017).

In South Africa, data was collected from three schools $(\mathrm{N}=3)$, including both semi-urban and urban primary schools. The numbers of teachers interviewed in the focus groups differed (four to five teachers per school), and 10 teachers were interviewed individually at two of the schools. In total, 23 teachers were interviewed, of which three were male and 20 were female. The Vaal Triangle area in South Africa from which the sample was drawn is an industrial area to which people migrate from all over the country for work, resulting in a diversity of ethnic groups and languages. The schools presented in the sample were representative of the different types of area schools, including those in areas with higher socio-economic levels and those in poverty-stricken areas, and all schools had students comprising a diverse mixture of cultural groups and home languages (English-as-secondlanguage students), as well as some students with hearing and visual disabilities and ADHDrelated symptoms (Authors, 2017).

Data collection methods. The following 3 data sources were used: semi-structured individual as well as group interviews with teachers who took part in Phase 1 and the field notes of the researchers, based on initial exploratory discussions with the teachers and the more formal interview process. The interview schedule for the interviews was based on the results of Phase 1 and the following questions guided the further exploration of how teachers enact inclusive education against the background in general of their attitudes and sense of self-efficacy:

If you look at/think of your own classroom, how do you deal with all the children and their needs in your classroom? 
If you talk of support for children in your classroom what do you mean?

As reported in Authors (2017), the South African interviews were conducted in English, since this is the language of learning and teaching at the schools that participated in this research. English is also the communal language used by different home language speakers to communicate with each other. Since Finnish is the official language in Finland, this was used in the Finnish interviews. Researchers in both countries reported that, because of the small size of the group interviews, all participants took adequate and equal part in them. The interviewers guided the participants according to the interview guidelines (and asked probing questions if more information was needed related to a comment. The average length of the interviews was 40 minutes for individual interviews and 69 minutes for group interviews. The interviews were conducted by a lead interviewer with a second interviewer acting as an observer, both of whom were study researchers (plus a master's student in some of the Finnish interviews.

The researchers employed field notes during the interviews to record phrases by the participants that could provide guidance for possible themes and future study investigations (Merriam, 2009). It was important to note descriptive details of the participants and the schools in order to organise and consequently acquire an appropriate sample profile.

Data analysis. The interview data was analysed using ATLAS.ti in accordance with the data analysis method decided upon for this project. ATLAS.ti is a specialised software package that allows a researcher to extract, categorise and interlink data segments from a large variety and volume of source documents (Friese, 2012). Structural coding was used to answer the research questions posed. As stated by M acQueen, structural coding applies to a content based or conceptual phrase representing a topic of inquiry to a segment of data that relates to a specific research question used to frame the interview (M acQueen as quoted in Saldanha, 2013, p. 84). The field notes of the researchers were analysed using content analysis (Authors, 2017).

Finally, all the data were consolidated using the evidence from the data sources in both countries. To verify the trustworthiness of the data analysis, triangulation of the data, including a comparison of the different data sources to verify themes across all sources, was employed (Leatherman \& Niemeyer, 2010). The data from both countries were then compared during a final comparative data analysis phase.

\section{- Phase III: Meta-inferences}

As pointed out by Creswell and Plano Clark (2007, p. 83), a study that includes both quantitative and qualitative data without explicitly mixing the data derived from each is simply a collection of multiple methods. In this project, quantitative data (i.e. measurements) were first connected during the intermediate phase to the qualitative data by using the quantitative findings to build towards the subsequent collection and analysis of qualitative data (i.e. meanings; Teddlie \& Tashakkori, 2009). Including a third phase is not 
the usual custom in sequential, explanatory mixed-methods designs, due to the fact that the mixing of data usually takes place in the intermediate phase (Creswell \& Plano Clark, 2007). However, we decided to further integrate all the findings in a final phase to refine the statistical results and the views expressed by participants during the interviews in the qualitative phase in order to develop more in-depth knowledge of participants' perspectives and actions. By using a meta-inference process (i.e. defining inferences as interpretations and conclusions) in Phase III, the researchers also hoped to provide insight into different aspects of the same phenomena and provide a more complete picture for this cross-cultural study (Teddlie \& Tashakkori, 2009).

\section{- Summary of research process}

Table 2. Visual representation of research process (based on Creswell \& Plano Clark, 2007)

\begin{tabular}{|c|c|c|}
\hline Phases & Procedure & Product \\
\hline \multicolumn{3}{|l|}{ Phase 1: Measurements } \\
\hline QUAN data collection & $\begin{array}{l}2 \text { questionnaires } \\
\text { N =SA: 319; Finland: } 822\end{array}$ & Numeric data \\
\hline QUAN data analysis & $\begin{array}{l}\text { Data screening, descriptive stats } \\
\text { and comparisons }\end{array}$ & $\begin{array}{l}\text { Numeric indexes, frequencies, } \\
\text { factor loadings }\end{array}$ \\
\hline $\begin{array}{l}\text { Connecting QUAN \& QUAL } \\
\text { phases: The intermediate } \\
\text { phase }\end{array}$ & $\begin{array}{l}\text { Purposefully selecting } \\
\text { participants, developing } \\
\text { interview questions based on } \\
\text { quantitative findings }\end{array}$ & $\begin{array}{l}\text { Number of participants } \\
\text { identified, } \\
\text { interview schedule/protocol }\end{array}$ \\
\hline \multicolumn{3}{|l|}{ Phase 2: Meanings } \\
\hline QUAL data collection & $\begin{array}{l}\text { Individual and focus group } \\
\text { interviews }\end{array}$ & $\begin{array}{l}\text { Text data: transcripts, } \\
\text { documents, codes and themes }\end{array}$ \\
\hline QUAL data analysis & $\begin{array}{l}\text { Document analysis, thematic } \\
\text { analysis: constant comparative } \\
\text { method and } \\
\text { within and across country } \\
\text { comparisons }\end{array}$ & $\begin{array}{l}\text { Similar and different themes } \\
\text { and categories }\end{array}$ \\
\hline \multicolumn{3}{|l|}{ Phase 3: Meta-inferences } \\
\hline $\begin{array}{l}\text { Integration of QUAN } \\
\& \text { QUAL results in a } \\
\text { meta-inference phase } \\
\text { (Teddlie \& Tashakkori, } \\
\text { 2009) }\end{array}$ & $\begin{array}{l}\text { Further meta-interpretation and } \\
\text { discussion of merged QUAN } \\
\text { results and QUAL findings }\end{array}$ & $\begin{array}{l}\text { Discussion, Implications, future } \\
\text { research }\end{array}$ \\
\hline
\end{tabular}

\section{Data analysis and phase findings}




\section{- Phase I: Measurements}

The quantitative data were measured using different statistical analyses and have been reported in several earlier papers. In summary, our comparative analysis indicated that, whereas the overall sentiment towards disabilities is positive in both countries, teachers have many concerns about the consequences of including children with disabilities in their classrooms. The overall attitudes towards inclusion are relatively neutral in both countries, but there are also differences. Finnish teachers' sentiments toward interacting with persons with disabilities were very positive and more positive than those of the South African teachers (Authors, 2012a), who until recently did not generally have students with disabilities in their mainstream classrooms. However, a comparison of predictors of self-efficacy showed that interactions with persons with disabilities had a positive effect on the efficacy of South African teachers, whereas a similar relationship was not found in Finland (Authors, 2013c). General attitudes toward including students with disabilities in mainstream classes were also more positive in Finland, but they still were slightly below the neutral midpoint of the scale. In contrast, South African teachers were less concerned about the inclusion of students with disabilities in their own classrooms than their Finnish counterparts were. Furthermore, South African teachers showed no difference between the general idea of inclusion and the specific idea of recognising human rights by including students with disabilities in their own classrooms, whereas Finnish teachers gave a clear indication of being more critical than South African teachers about the specific implementation of inclusive education (Authors, 2012a). On the other hand, the analysis of predictors of self-efficacy showed that only among Finnish teachers did previous training on inclusive education have a significant effect on the level of self-efficacy. While such a relationship was not found in South Africa, there, participants' age predicted self-efficacy, unlike in Finland (Authors, 2013c). In both countries, there was a clear connection between self-efficacy and attitudes: the more teachers believed they could implement inclusive practices on a concrete and pragmatic level, the more positive their attitudes were towards inclusion. Self-efficacy in collaboration was particularly important in this regard (Authors, 2013b; Authors, 2012a).

\section{- Phase ll: Meanings}

The comparative qualitative findings indicated that the dynamic interaction between cultural-historical contextual issues, including policy, structure, school culture, as well as teachers' continuing, personal understanding of inclusive education, shapes the broader school context and determines how inclusion is enacted in classrooms and how teachers teach and support learners (Authors, 2017). As reported in 2017, daily teaching and learning activities in both countries are clearly related to the traditional view that students who are identified both informally and formally as having additional learning needs require additional, specialised and, in most instances, separate individualised teaching and learning strategies. Finnish teachers, who have a sophisticated support system to rely on when 
needed, tend to emphasise more innovative teaching and support strategies, including individual support in mainstream classrooms, peer teaching and the use of skilled classroom assistants to provide additional teaching support. On the other hand South African teachers who do not have access to adequate support systems, rely heavily on what they call 'classical teaching' based on a more traditional teacher-centred teaching approach. South African teachers also lack the well-developed pedagogical support network of their Finnish colleagues, and therefore, despite regarding the inclusion of students with diverse learning needs in their mainstream classrooms as these students' right within the South African cultural-historical context, such students remain on the periphery of classroom activities.

\section{- Phase III: Meta-inferences}

Although described separately in the previous two sections, the interactive nature of the quantitative and qualitative data became clear during its final merging. In both types of data, teachers' understanding of what they define as inclusive education can be seen to influence their perceptions in general, as well as what they regard as good classroom practices and their own level of self-efficacy in enacting what they regard as effective inclusion. Furthermore, these different data sources were especially helpful in providing a more accurate view of the way the diverse cultural-historical contexts within which they teach also crucially play a role in either supporting or creating obstacles for enacting inclusion in their classrooms. The interaction between both positive and negative classroom practices and contextual complexities, including the availability of adequate financial support in Finland and lack of adequate financial support in South Africa, affect the work of teachers, as reflected in the way in which they responded to the survey and interview questions. These responses clearly illustrate the way in which cultural-historical contexts either facilitate or obstruct inclusive education: for example, as indicated in the quantitative findings from South Africa, while teachers on the one hand showed positive attitudes based on their historical context and the resultant emphasis on human rights since 1994, the qualitative data clearly illustrates the contextual realities in a lower-income country that offer teachers few opportunities to realise these positive attitudes in concrete enactment of inclusive education through the acceptance and participation of every learner in their classrooms. This also highlights the importance of having evidence from several sources of data to provide insight into the complex cultural-historical factors that influence the effective implementation of inclusive education in both countries.

The following matrix in Figure 1 illustrates the complex interaction between the quantitative and qualitative findings related to individual and contextual factors that affect how inclusive education is implemented in the two countries. 


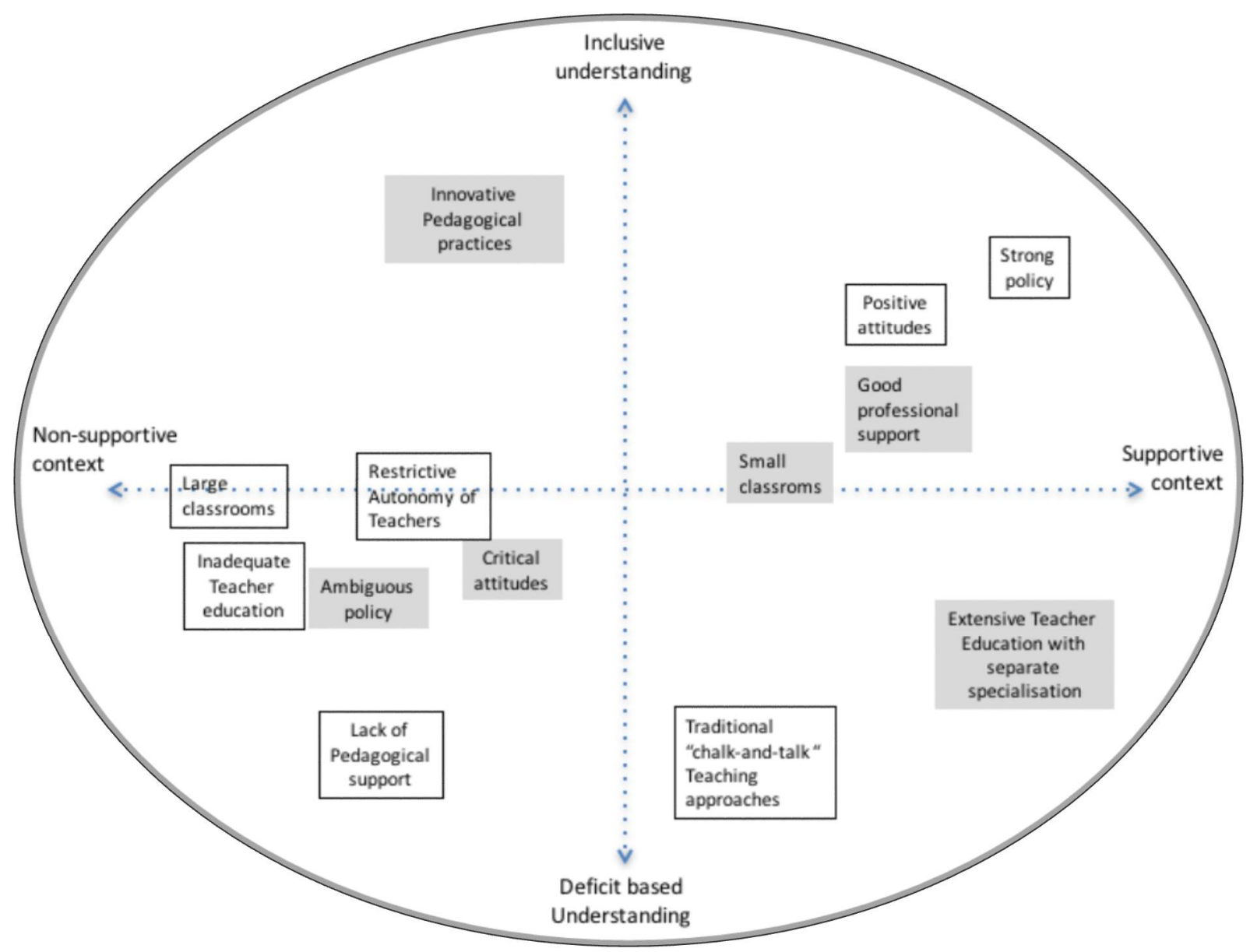

Figure 1. Factors that affect the enactment of inclusive education organised according to dimension of inclusiveness and supportiveness (boxes with white background refer to South Africa and boxes with grey background to Finland)

While it may be difficult to discuss in detail all the individual findings related to complexities and contradictions, after the data was finally merged it emerged that the following factors continuously interacted with one another: teachers' attitudes and pedagogical strategies, contents of initial teacher education programmes and the realities of the classroom, as well as idealistic policy formulation and its implementation and contextual realities.

\section{DISCUSSION}


Our meta-inference phase indicates that the development of inclusive education is a continuous and dynamic process that should be acknowledged more strongly.

Regarding attitudes, the authors found evidence of positive attitudes, especially among South African teachers, who were fully supportive of all learners' right to be taught in mainstream classrooms (Authors, 2012a). However, at the same time, their teaching strategies were influenced by the following challenges: teaching in overcrowded classrooms, not having much training on inclusive teaching and support strategies and having little if any professional support (Authors, 2016b; Department of Basic Education, 2015; Geldenhuys \& Wevers, 2013; Oswald, 2014; Swart \& Oswald, 2008; Walton, 2011). These contextual issues led teachers to fall back on the traditional medical-deficit model approach in responding to the diversity of learning needs in their classrooms. They preferred to refer learners whom they identified as having additional learning needs to specialists elsewhere, and they supported the idea of separate classrooms for these learners, despite their belief that these learners had a right to be in a mainstream classroom. In contrast, the Finnish teachers, who exhibited more critical attitudes towards including children with diverse learning needs in their classrooms, provided many examples of finding creative, inclusive solutions in their own classrooms. The high level of professional support they have available (e.g. part-time special education teachers and teaching assistants) clearly contributed to this contradiction (Authors, 2017; Jahnukainen \& Itkonen, 2016; Waitoller \& Artiles, 2013) However, it should be noted that having specialist support readily available might also affect Finnish teachers' attitudes indirectly by creating a tendency to think that teaching students with additional learning needs is dependent on the availability of specialised support.

It also became evident that differences in the quality and duration of initial teacher education programmes had consequences on the way teachers enacted inclusive education in their classrooms. In Finland, all teacher education is at the master's level (except for kindergarten teachers), but programmes are directed towards specialisation (e.g. classroom teachers, subject teachers, special education teachers and guidance counsellors). These programmes are largely separate, and they lead to teachers developing a strong professional identity related to their specific line of study, which creates collaboration and cooperation challenges when they start working with their colleagues in schools (Authors, 2012b, Paju et al., 2016). Our findings indicate that efficacy in collaboration influences attitudes (Authors, 2012a), and in this case, having separate identities as teachers may contribute to the quality of the further development of collaborative partnerships within schools. In South Africa, teachers link their lack of confidence in enacting inclusive education in their classrooms with their initial teacher education experiences, which follow an add-on approach of providing one or two specific modules on inclusive education with an emphasis on learners with disabilities (Authors, 2013b; Walton \& Ruznyak, 2016).

Finally, while a strong policy that supports inclusion is important, that alone does not create inclusive school environments, as witnessed in the schools studied in South Africa. Many of the contextual challenges, including the lack of adequate funding leading to a lack of professional 
pedagogical support structures, downplay the possibilities created by policy that tends to be idealistic (Nel et al., 2011). This finding is confirmed by a report by the Department of Basic Education in 2015 that indicates that disparities across the provinces in resourcing inclusive education and improving access to education and support for learners who are experiencing diverse barriers to learning, including personnel provisioning and finance (some provinces have no or very few professional support staff appointed at district level and the building of new special schools happens without accompanying planning for staff provision) exacerbate the situation (DBE, 2015). This creates, for example, the contradiction between the positive attitudes towards inclusive education and lack of confidence in its implementation among South African teachers (Authors, 2017; Department of Basic Education, 2015, Nel et al. 2016). On the other hand, in Finland, where the policy is in general favourable for inclusion but quite ambiguous due to its leaving decisions on access to local authorities (Tahvanainen, 2011), our merged findings show contradictions in creating inclusive education contexts. As a result of localization, municipalities in which schools are located have opted for very different strategies, and different strategies can even exist in schools within the same municipality. This is shown on a larger scale in national statistics, which show for example that the share of students identified as needing special support varies from $5-11 \%$ in the 19 mainland regions of Finland (OSF, 2015).

Within the South African context, after decades of a strong deficit approach to diverse educational needs, inclusive education is now clearly connected to a broader human rights and equity agenda for all students in mainstream schools (Geldenhuys \& Wevers, 2013; Walton, 2011). Our meta-inference phase indicates that the context-knowledge and confidence variable has the lowest relationship with attitudes in South Africa, which has a stronger focus on equality of access to mainstream classrooms and the more inclusive education policy of the two countries. On the other hand, although Finland is ambiguous in its terminology and policy related to inclusive education, as well as its implementation, the education system continues to emphasise the pragmatic implications of general access to mainstream classrooms, with the result that practical knowledge and related confidence more strongly predicts attitudes in Finland than in South Africa (Authors, 2012a; Jahnukainen \& Itkonen, 2016).

As indicated by Shogren, M cCart, Lyon and Sailor (2015) the integration of knowledge of classroom practices, teacher perspectives and attitudes, available contextual support to teachers and students and levels of policy implementation influences the ways in which inclusive education policy is realised within school communities worldwide. However, as our findings indicate, progress in the implementation of inclusive education and challenges in this regard should also be linked to an understanding of the interaction between unique local historical and socio-cultural contemporary contexts within individual countries and the resultant development of localised versions of inclusive education in which teachers could play a meaningful role.

\section{CONCLUSION}


In conclusion, our meta-inferences suggest that developing inclusive education requires a dynamic and interactive approach that not only involves policymakers and teacher educators but also teachers in classrooms within unique country contexts. Even extensive initial education of teachers in inclusive practices is not likely to have a great effect if the broader context - including, for example, available professional support services, policy guidance and the development of strong identities as effective teachers of learners with diverse educational needs - does not support adopting new and more inclusive ways of teaching. On the other hand, having good policies and demand from organisations that support the notion of inclusive education will not lead to the enactment of inclusive education (as understood internationally, that is, as the acceptance and participation of all learners), if teachers are not supported effectively to become willing and capable of changing their traditional ways of thinking about teaching students with diverse educational needs. The continuous, dynamic interaction between these factors cannot be ignored.

Another clear conclusion is that mixed-methods research offers a powerful tool to carry out international comparative education research in future and enhances understanding of complex phenomena such as inclusive education. As reported, there were contradictory findings between the qualitative and quantitative results in both contexts, requiring a more in-depth integration for consistent meta-inferences to emerge. Integration of the findings and conclusions from each phase of the project in the third phase, enabled the researchers to create new meanings and new understandings about the non-linearity and complexity of implementing inclusive education in two diverse countries and how cultural-historical contexts shape the ways in which teachers enact inclusive education in their own classrooms.

\section{ACKNOWLEDGEMENT}

We would like to acknowledge and thank all the colleagues who at times, however briefly, joined us on our mixed-methods and inclusive education research journey, without your supportive collaboration this research journey could not have been completed. 


\section{REFERENCES}

Aldridge, J. M., Fraser, B. J., \& Huang, T. I (1999). Investigating classroom environments in Taiwan and Australia with multiple research methods. Journal of Educational Research, 93(1), 48-62.

Authors. (2012a). Details omitted for double-blind peer reviewing. Authors. (2012b). Details omitted for double-blind peer reviewing. Authors. (2013). Details omitted for double-blind peer reviewing.:

Authors. (2013b). Details omitted for double-blind peer reviewing.

Authors. (2013c) Details omitted for double-blind peer reviewing.

Authors. (2014). Details omitted for double-blind peer reviewing.5[

Authors. (2015). Details omitted for double-blind peer reviewing.[is]

Authors. (2016a). Details omitted for double-blind peer reviewing.sp]

Authors. (2016b). Details omitted for double-blind peer reviewing.5s:

Authors. (2017). Details omitted for double-blind peer reviewing.:

Creswell, J. W., \& Plano Clark, V. L. (2007). Designing and conducting mixed methods research. London: SAGE Publications.

Department of Education. (2001). Special needs education: Building an inclusive education and training system (Education White Paper 6). Pretoria: Government Printer.

(DBE) Department of Basic Education. (2010). Guidelines for inclusive learning programmes. Pretoria: Government Printer.

Department of Basic Education. (2015). Report on the implementation of Education White Paper 6 on inclusive education: An overview for the period 2013-2015. Pretoria: Government Printer. 
Ferri, B. A. (2015). Integrazione scholastica: On not having all of the answers - a response to Anastasiou, Kauffman and Di Nuovo. European Journal of Special Needs Education 30(4): 444-447.

Finnish Basic Education Act. (2010). Laki perusopetuslain muuttamisesta (642/2010) [Basic Education Acts, Amendments up to 642/2010]. Retrieved on $24 \mathrm{M}$ arch, 2017 from: http://www.finlex.fi/fi/laki/alkup/2010/20100642

Florian, L. (2014). What counts as evidence of inclusive education? European Journal of Special Needs Education, 29(3), 286-294.

Friese, S. F. (2012). ATLAS.ti 7 Quick tour. Berlin: ATLAS.ti Scientific Software Development $\mathrm{GmbH}$.

Geldenhuys, J.L., \& Wevers, N.E.J. (2013). Ecological aspects influencing the implementation of inclusive education in mainstream primary schools in the Eastern Cape, South Africa. South African Journal of Education, 33(3), 1-18.

Jahnukainen, M . \& Itkonen, T. (2016). Tiered intervention: history and trends in Finland and the United States. European J ournal of Special Needs Education, 31(1), 124-139.

Jordan, A., Schwartz, E. \& M cGhie-Richmond, D. (2009). Preparing teachers for inclusive classrooms. Teaching and Teacher Education, 25, 535-542.

Kington, A., Sammons, P., Day, C., \& Regan, E. (2011). Stories and statistics: Describing a mixed methods study of effective classroom practice. Journal of M ixed M ethods Research, 5(2): 103-125.

Kivirauma, J., K. Klemelä, and R. Rinne. (2006). "Segregation, Integration, Inclusion- The Ideology and Reality in Finland." European Journal of Special Needs Education 21 (2): 117-133.

Kozleski, E. B., Artiles, A. J., \& Waitoller, F. R. (2011). Equity in inclusive education: Historical trajectories and theoretical commitments. In A. J. Artiles, E. B. Kozleski, \& F. R. Waitoller (Eds.), Inclusive education: Examining equity on five continents (pp. 1-14). Cambridge, MA: Harvard Education Press.

Leatherman, J. M ., and Niemeyer, J. A. (2010). Teachers' attitudes towards inclusion: Factors influencing classroom practice. Early Childhood Teacher Education 26(1): 23-36.

Loreman, T., Earle, C., Sharma, U., \& Forlin, C. (2007). The development of an instrument for measuring pre-service teacher's sentiments, attitudes and concerns about inclusive education. International Journal of Special Education, 22(2), 150-159.

Merriam, S. (2009). Qualitative research: A guide to design and implementation. San Francisco, CA: Jossey-Bass.

Mertens, D. M. (2005). Research and evaluation in education and psychology: Integrating diversity with quantitative, qualitative, and mixed methods. London: SAGE Publications. 
M inistry of Education and Culture. (2007). Special education strategy. Reports of the M inistry of Education, Finland, No. 47. Helsinki: M inistry of Education and Culture.

National Board of Education. (2010). Perusopetuksen opetussuunnitelman perusteiden 2004 muuttaminen ja täydentäminen [Changing and supplementing the national core curriculum for basic education]. Helsinki: Finnish National Board of Education.

Nel, N., M uller, H., Hugo, A., Helldin, R., Backman, O., Dwyer, H., \& Skarlind, A. (2011). A comparative perspective on teacher attitude-constructs that impact on inclusive education in South Africa and Sweden. South African Journal of Education, 31(1), 7490.

Nel, N., Tlale, D., Engelbrecht, P. \& Nel, M . 2016. Teachers' perceptions of education support structures in the implementation of inclusive education in South Africa. KOERS-Bulletin for Christian Scholarship, 81 (3). Available at https:// doi.org/10.19108/KOERS.81.3.2249.

Official Statistics of Finland. (2011). Erityisopetus [Special education]. Retrieved on 21 March from: http://www.stat.fi/til/erop/2011/index_en.html

Official Statistics of Finland. (2015). Special education: Intensified or special support was received by 16 per cent of comprehensive school pupils. Helsinki: Statistics Finland. Retrieved on 21 M arch from: http://www.stat.fi/til/erop/2015/erop_2015_2016-0613_tie_001_en.html.

Oswald, M. (2014). Positioning the individual teacher in school-based learning for inclusion. Teaching and Teacher Education 37, 1-10.

Paju, B., Räty, L., Pirttimaa, R., \& Kontu, E. (2016). The school staff's perception of their ability to teach special educational needs pupils in inclusive settings in Finland. International J ournal of Inclusive Education, 20(8), 801-815.

Pesonen, H., Kontu, E., Saarinen, M., \& Pirttimaa, R. (2016). Conceptions associated with sense of belonging in different school placements for Finnish pupils with special educational needs. European Journal of Special Needs Education, 31(1), 59-75.

Republic of South Africa (RSA). 1996a. Constitution of the Republic of South Africa. Pretoria: Government Printer.

Robinson-Pant, A., \& Singal, N. (2013). Editorial: Researching ethically across cultures: Issues of knowledge, power and voice. Compare, 43(4), 417-421.

Saldana, J. (2013). The Coding M anual for Qualitative Researchers. Los Angeles: Sage

Sharma, U., Loreman, T., \& Forlin, C. (2012). M easuring teacher efficacy to implement inclusive practices. Journal of Research in Special Educational Needs, 12(1), 12-21.

Shogren K.A., M cCart, A.B., Lyon, K.J . \& Sailor, W.S. (2015). Research and Practice for Persons with Severe Disabilities, 40(3), 173-191. 
Swart, E., \& Oswald, M. (2008). How teachers navigate their learning in developing inclusive learning communities. Education as Change, 12(2), 91-108.

Tahvanainen, S. (2011). "Inkluusio sivistysvaliokunnan silmin [Inclusion from the Perspective of the (Parliamentary) Committee for Education and Culture]." M aster's diss., University of Eastern Finland.

Takala, M ., Pirttimaa, R., \& Törmälä, M. (2009). Inclusive special education: the role of special education teachers in Finland. British Journal of Special Education, (36), 3, 162172.

Teddlie, C., \& Tashakkori, A. (2009). Foundations of mixed methods research: Integrating quantitative and qualitative approaches in the social and behavioural sciences. London, UK: SAGE.

UNESCO. (2009). Policy guidelines on inclusion in education. Paris: UNESCO.

Waitoller, F.R. \& Artiles, A. (2013). A decade of professional development research for inclusive education: a critical review and notes for a research program. Review of Educational Research 83(3), 319-356.

Walton, E. (2011). Getting inclusion right in South Africa. Intervention in School and Clinic, 46(7), 240-245.

Walton, E. \& Rusznyak, L. (2016). Choices in the design of inclusive education courses for pre-service teachers: the case of a South African university. International Journal of Disability, Development and Education, 64(3), 231-248. 